Acta Technologica Agriculturae 4

Nitra, Slovaca Universitas Agriculturae Nitriae, 2015, pp. 122-125

\title{
ACOUSTIC EMISSION WITH TESTING THE PRESSURE RESISTANCE AND STRUCTURAL INTEGRITY IN MINERAL FEEDS
}

\author{
Jaroslav ZAČAL*, Petr DOSTÁL, Michal ŠUSTR \\ Mendel University in Brno, Czech Republic
}

\begin{abstract}
This work deals with a specific method of non-destructive testing - acoustic emission. The theoretical part of the article is focused on the underlying principle of this method and its applicability. The experimental part is focused on the research of pressure resistance in mineral feed using acoustic emission. Mineral feed is a condensed cube of rock salt (sodium chloride) with supplementary minerals, which is fed to livestock and game to supply the mineral elements necessary for their health and condition. Acoustic emission gives the overview of internal changes in material structure. With use of specific software we can interpret the acoustic signal and identify the current state of material integrity in real time.
\end{abstract}

Keywords: acoustic emission; non-destrucitve metod; mineral feed; pressure resistance

Mineral feeds are compacted cubes of rock salt with added mineral nutrients, which are fed to livestock and game. The level of mineral nutrients in animal diet has a direct influence on their condition and health. This is of utmost importance especially for herbivores who intake excess of potassium in forage and pasture grass (Losertová, 2007).

The topic of this study is assessment of mineral feed durability against pressure tension. For an exact description of destruction progress in material, the acoustic emission (AE) method was selected (Fiala et al., 2003). Acoustic emission is a non-destructive passive method, which means it does not affect the examined object and reports integral information considering the momentary dynamic state of material, which is considered its main benefit. Acoustic emission signals are caused by dynamic structural changes in material and manifest themselves as a gradual elastic wave. The source of these wave hits is a sudden release of energy in material. This process accompanies deformational, break, respective phase changes in material (Kopec, 2008).

\section{Material and methods}

\section{Acoustic emission}

A Xedo analyser (Fig. 1) manufactured by a Dakel company is a modern high-performance modular apparatus for measuring and analysing the parameters of acoustic emission. The analyser is designated for connecting the passive piezoelectric corundum sensors without the amplifier, or active sensors with integrated pre-amp supplied with $12 / 24 \mathrm{~V}$. Processing of signal sampled in $2-8 \mathrm{MHz}$ with 12 -bit resolution is fully digital. For this specific case of measuring, we selected an IDK-09 sensor with a corundum connection plate (Figure 2).

For the testing set of mineral feed samples, the optimum dimensions were suggested, which represent real

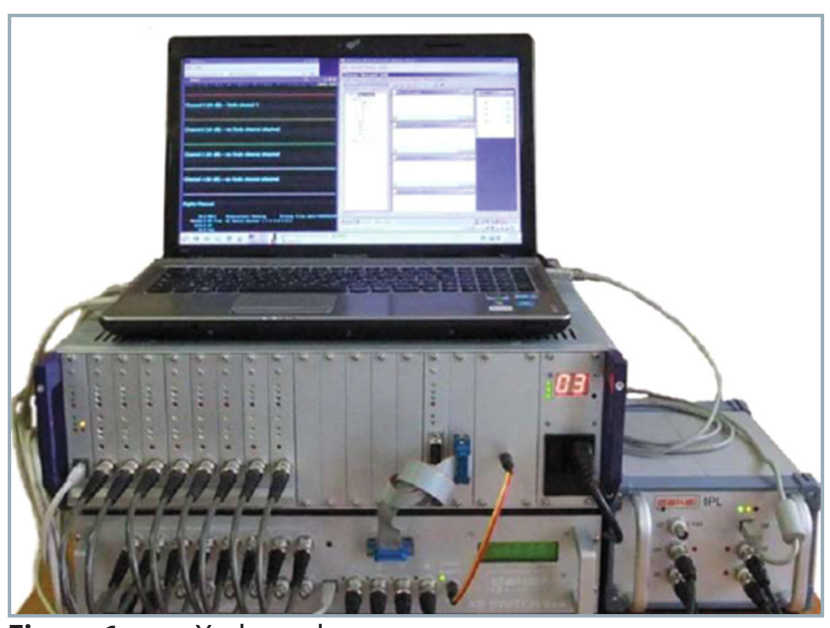

Figure $1 \quad$ Xedo analyser

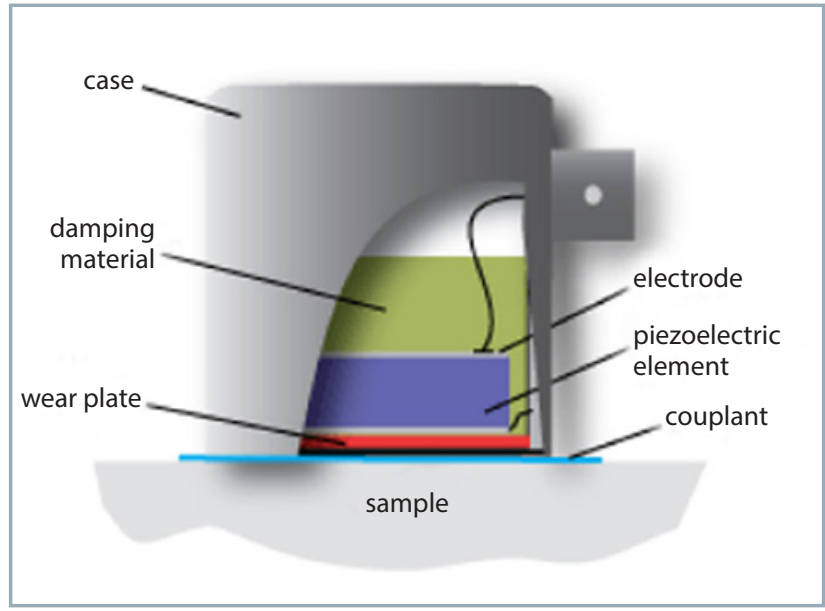

Figure 2 Sensor of acoustic emission 

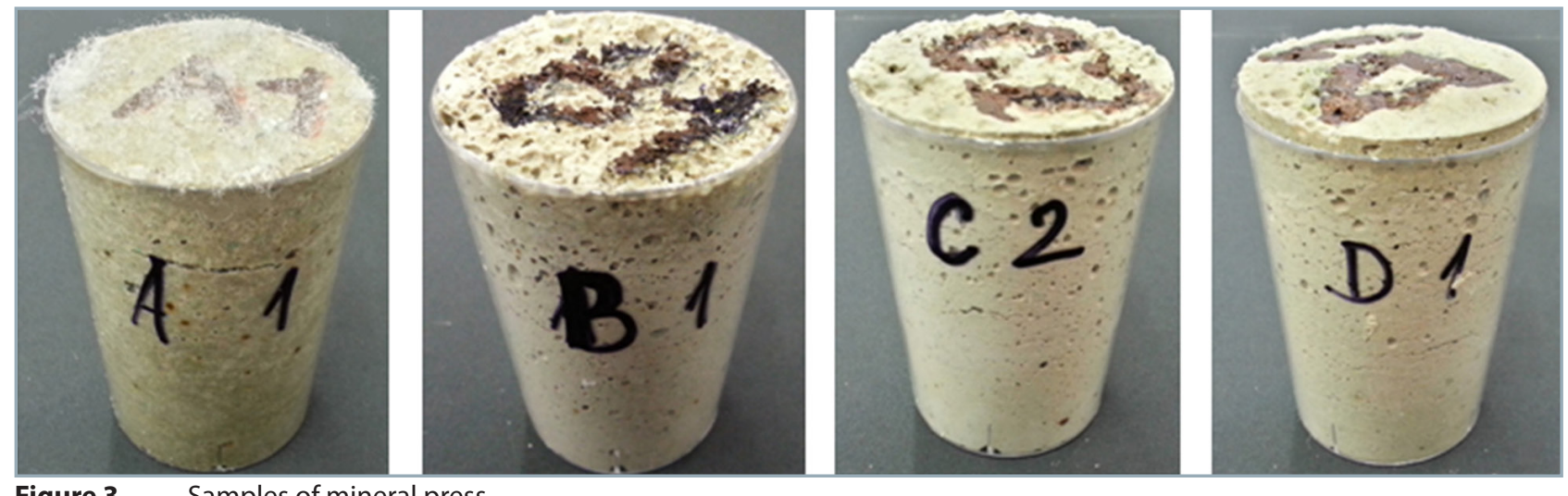

Figure $3 \quad$ Samples of mineral press

dimensions in a $1: 5$ ratio for pressure testing. The tested object was shaped in truncated cone shape (Figure 3). For precise measurement, the top and bottom surfaces were milled perpendicular to its longest axis. On the sample surface, a notch was filed for easier fixation of the sensor to ensure better contact between the sample and sensor.

Examined samples were divided into 4 different groups (A, B, C, D), each containing 10 samples. Each group of samples represented different characteristics, which were compared with each other. For designating the best variety of sample durability, the least favourable variant should be considered, in our case the worst values occur in the groups $B$ and $C$. For further experiment, the samples of the $A$ and $D$ groups were selected. Samples were fitted with the piezoelectric $A E$ sensor for detailing characteristic assessment.

\section{Course of assessment}

For testing the pressure resistance of mineral feeds, we have used the manual press. Individual samples were placed into the mechanical press (Kopec, 2008). Tested samples were subjected to a constant pressure of $10 \mathrm{~mm} \cdot \mathrm{min}^{-1}$. It is possible to record the continuous deformation and log the acoustic emission signals in this process (Pazdera et al., 2004). To obtain accurate results, the measuring system needed to be calibrated according to specific prerequisites for material using the pentest in Table 1.

The root mean square (RMS) of AE was observed. This parameter means the effective signal value. In alternating current, RMS is equal to direct current value, which after employment of resistance load would exhibit the same average performance. The RMS is reported in the range of
$\mathrm{mV}$. This value describes the quantitative characteristic of measured $A E$ events (quantum of energy).

Table 1 Configuration of the Xedo measuring apparatus
\begin{tabular}{|l|c|}
\hline Setting the configuration for AE & Value \\
\hline Amplifier & $5 \mathrm{~dB}$ \\
\hline Starting event & 110 \\
\hline Ending event & 110 \\
\hline Count 1 & $102 \mathrm{mV}$ \\
\hline Count 2 & $200 \mathrm{mV}$ \\
\hline
\end{tabular}

Acoustic emission signals in pressure testing were recorded with one corundum piezoelectric pickup sensor Dakel, fixed in the upper part of tested sample with a spring-loaded clip. To ensure the optimal acoustic transfer between the sensor and material, we used 'ultrasonic gel' The primary function of cohesive medium is to repel the air present between contact surfaces, thus to enhance the signal transfer (Askeland et al., 2006).

For individual samples in experiment, the unified testing procedure was used. Data were measured consecutively in whole test duration with the AE system installed on the testing apparatus, see Figure 4.

\section{Results and discussion}

Parameters were assessed with the mean level of detected signal - RMS and the count of overshoots over threshold levels in selected intervals. The measuring system Daemon

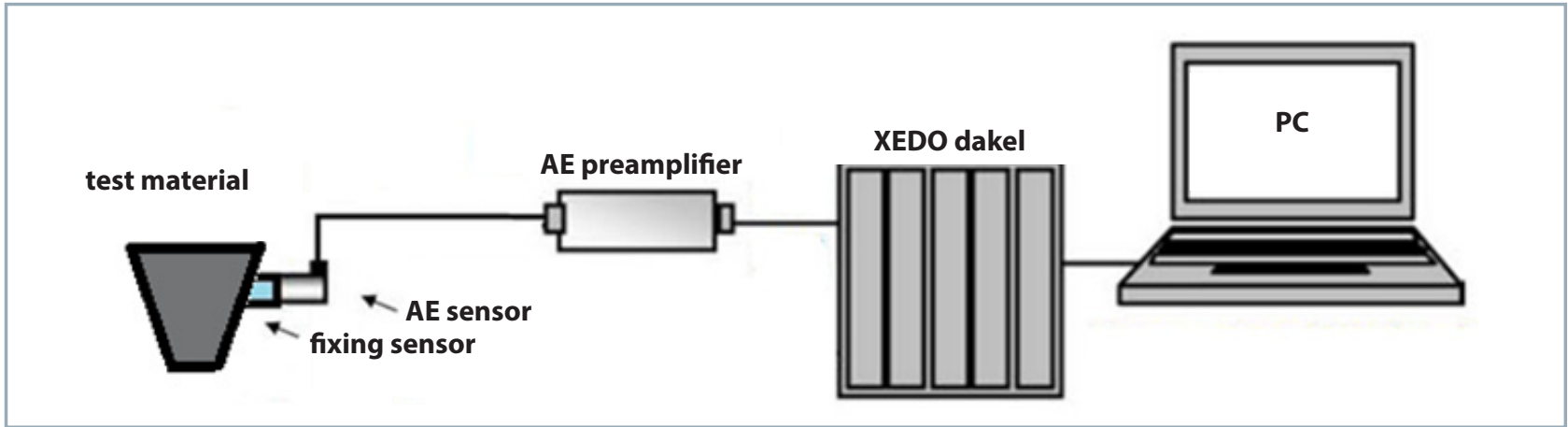

Figure 4 Mounting diagram of sample and acoustic emission sensor at a test facility 


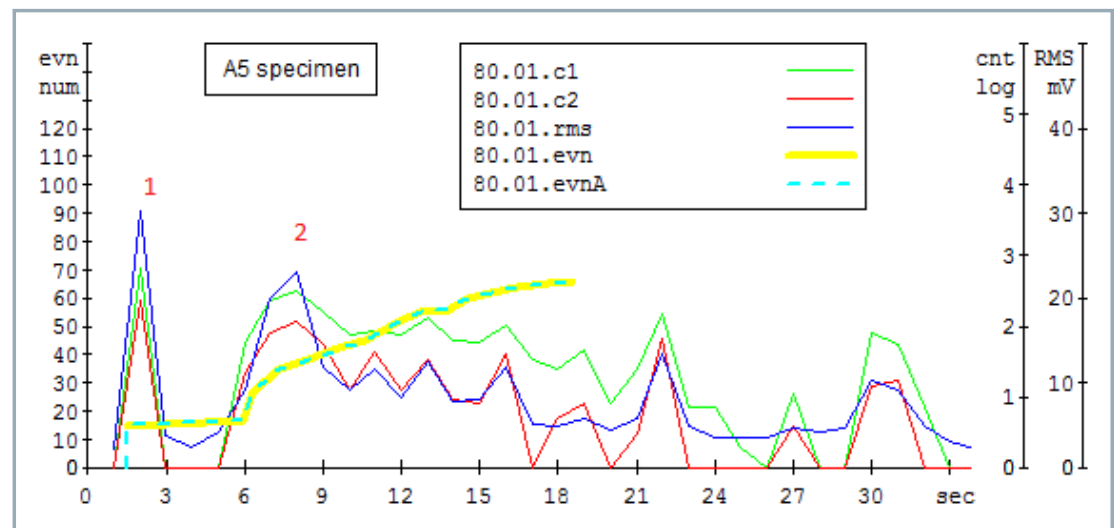

Figure 5 Representative parameters of acoustic emission output from the specimen A5

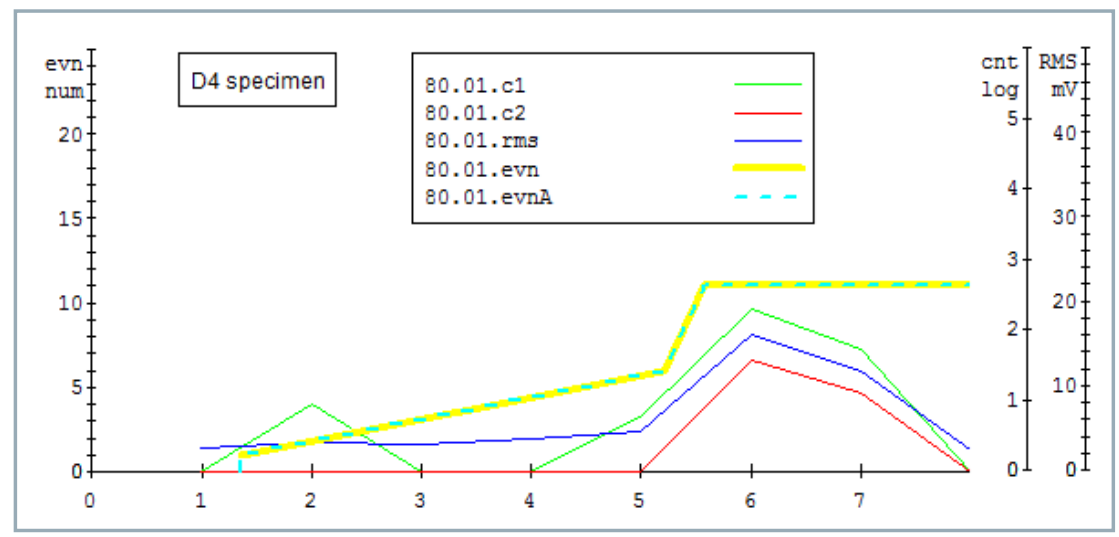

Figure 6 Representative parameters of acoustic emission output from the specimen D4
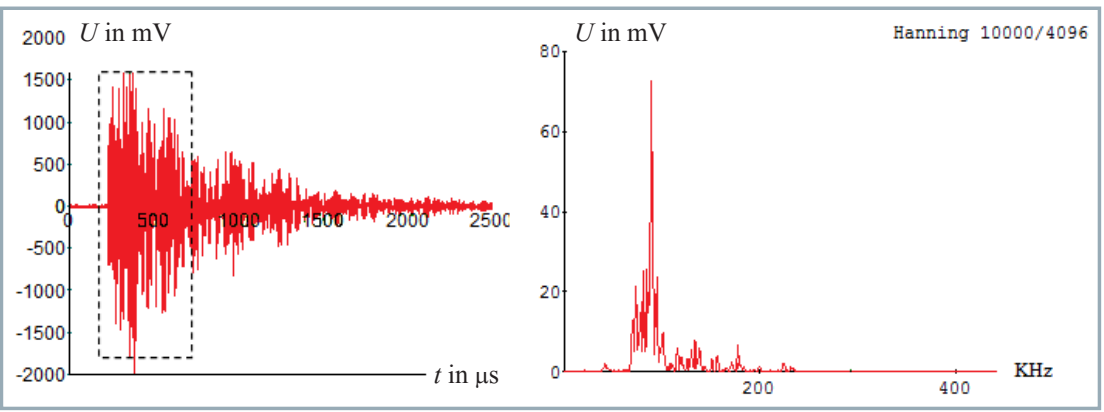

Figure 7 Representative acoustic emission event and PSD functions for the specimen A5

evaluates RMS and overshoots count in two threshold levels (Count 1 and Count 2).

In Figure 5 it is clear to distinguish two relevant periods of $A E$ signal. The first signal (1) was recorded to the third second of pressure application, and the second signal (2) took place from the fifth to ninth second and further with descending trend until the end of testing. This means that the first signal emission is an indicator of rapid destruction in material. The second rapid emission with the following descending trend indicates consecutive crushing, in which structure cohesion decreases.

From the test results of the A5 sample it is obvious that the maximum RMS is approximately $30 \mathrm{mV}$ in the first period $\mathrm{kHz}$ in the sum of both measurements. The sample is hard and fragile, structure has low resistance to pressure load. The sample still shows distinctive cohesion, which continuously ceases from the eighteenth second of load, when crumbling of sample begins.

Figure 5 shows high $\mathrm{AE}$ periods of mineral feed. The count of local deformation damage corresponds to $A E$ events with high peak amplitude and low peak of frequency. Some of new cracks are not 'heard' by the sensors. Hypothetically, these continuing events can be related to propagation of the earlier formed cracks. However, for all observed cracks, it is not possible to get the correlations of all individual readings of $A E$ events locations. High AE periods should represent failure material (Masmoudi et al., 2015), which can be observed in the figure; therefore, these events do enter the analysis of mineral feed cracking.

Figure 6 represents the record of acoustic emission for the sample D4. There is visible continuous destruction of material without a significant primary $A E$ impulse, thus without primary rapid destruction of structure. Cohesion is lost gradually. From the fifth second, there are distinctive accented acoustic manifestations in the process of crumbling of material.

From the test results of the D4 sample, it is certain that the maximal RMS is achieved at $15 \mathrm{mV}$ in the first period and $\mathrm{AE}$ frequency is $75 \mathrm{kHz}$ in both temporal periods.

Table 2 Displays parameters of RMS and frequency of AE signal for individual specimens

\begin{tabular}{|l||c|c|c|}
\hline Specimen & Specimen density $\boldsymbol{\rho}$ in $\mathbf{~ g g} \cdot \mathbf{m}^{-\mathbf{3}}$ & Maximum root mean square (Max RMS) in $\mathbf{~} \mathbf{V}$ & Maximum numer of events in $\mathbf{~ k H z}$ \\
\hline A5 & 1347.875 & 30 & 90 \\
\hline D4 & 1259.133 & 15 & 75 \\
\hline C3 & 1003.372 & 10 & 29 \\
\hline B3 & 1017.412 & 9 & 21 \\
\hline
\end{tabular}




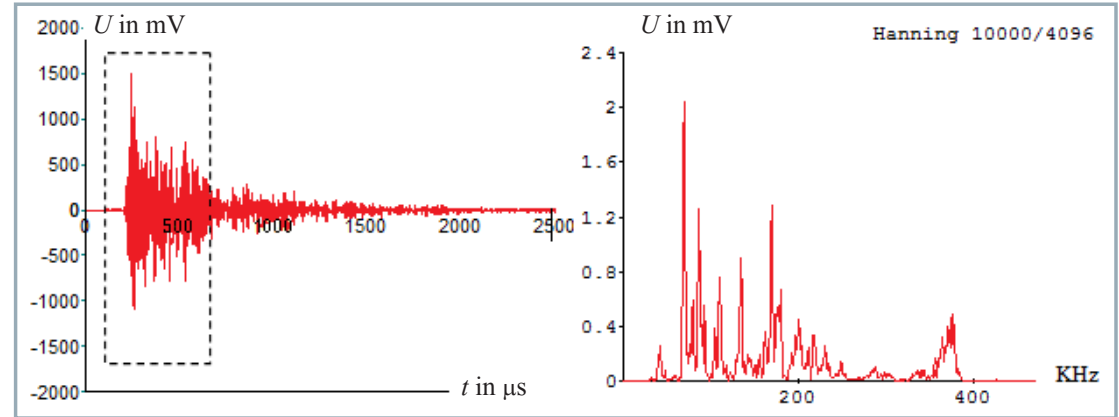

Figure 8 Representative acoustic emission event and PSD functions for the specimen D4

The highest RMS was reported for the A5 sample as well as the highest count of recorded signals. The D4 samples show lower values of the RMS parameter. From this we can conclude that the samples from the A4 group show higher resistance to primary destruction of structure, which occurs earlier than in tougher samples of the D group.

Figures 7 and 8 display the sample of signal on the left and on the right the frequency analysis of signal (Power Spatial Density - PSD function), which expresses the AE signal energy. The horizontal axis in the right window of PSD function designates the frequency in $\mathrm{kHz}$, and the vertical axis represents energy in $\mathrm{mV}$. The PSD function characterises the samples of individual events of $A E$ and represents the overview of frequency constituents of the signal. The assessment of experiment was conducted by visual comparison of PSD functions with a goal to distinguish the most important phenomena occurring in both diagrams and determination of basic mapping of both signals.

Representing A5 sample of $\mathrm{AE}$ (see Figure 7 right) determines the selective area for the PSD analysis. The maxima of recordable events for the PSD function occurred at $90 \mathrm{kHz}$. This information indicates the part of acoustic signal recordable at initiation of destructive fissure. The analysis of sample indicates the wider amplitude. The energy of the signal is therefore higher. It is possible to claim that the mechanical resistance of group samples is higher than the resistance of the D group. Primary destruction of material occurs from the third second further, but is followed by gradual disintegration of material.
The samples of AE signal and PSD analysis at representative sample D4 (see Figs. 6, 8) display lower values of PSD. There is obvious the descending trend of signal energy. From this we can conclude that cohesion of material is disturbed continually without discernible fatal breaks.

\section{Conclusion}

From the pilot experiment we can deduce the whole palette of new discoveries. It was concluded that samples subjected to stress show the obvious declination of values.

The experiment was focused on measuring the resistance of mineral feed subjected to mechanical pressure. Conducted tests revealed better characteristics in the group A, which show better resistance compared to other variants. The samples of the $A$ category resist greater pressure, but disintegrate after pressure application, while the samples of the D category disintegrate gradually. Considering the number of samples in the group, this claim is statistically conclusive.

Modern instrumentation and pattern recognition helps, but operator training and procedures still play a major part in achieving meaningful measurements (Cole, 2005).

The experiment showed the applicability of AE survey for analysis and represented an interesting view on the behaviour of internal AE sources in the structure of material subjected to mechanical pressure stress testing. From this hypothesis we can conclude that applicability of $A E$ represents a viable approach for further research. One perspective application of this method is development of automated measuring institute for quick continuous sample analysis.

\section{Acknowledgement}

The research has been supported by the project IP 21/2015 'Monitoring of quality of composite materials in agricultural environment' financed by the Internal Grant Agency of Agronomic Faculty, Mendel University in Brno.

\section{References}

ASKELAND, D. - PHULÉ, P. 2006 The Science and Engineering of Materials. $5^{\text {th }}$ edition. Toronto : Thomson, $863 \mathrm{pp}$.

COLE, P. - WATSON, J. 2005. Acoustic emission for corrosion detection. In Middle East Nondestructive Testing Conference \& Exhibition. Bahrain, Manama : NDT. net, pp. 27-30.

ČSN 1330-9. 2001. Non-destructive testing - Terminology. Part 9: Terms used in acoustic emission testing.

FIALA, J. - MENTL, V. - ŠUTTA, P. 2003 Structure and Properties of Materials. $1^{\text {st }} \mathrm{ed}$. Praha : Academia, 572 pp.

KOPEC, B. 2008. Non-destructive testing of materials and structures. Materials Science IV. $1^{\text {st }}$ ed. Brno : Academic Publishing CERM, $571 \mathrm{pp}$.

LOSERTOVÁ, M. 2007. Introduction to Materials Science. Ostrava : VŠB-TU Ostrava. MASMOUDI, S. - EL MAHI, A. - TURKI, S. 2015 Use of piezoelectric as acoustic emission sensor for in situ monitoring of composite structures. In Composites, 80 pp. Part B-Engineering Elsevier Sci Ltd, The Boulevard, England.

PAZDERA, L. - SMUTNÝ, J. - MAZAL, P. 2004. The use of acoustic emission method in monitoring the properties of loaded materials and structures. Brno : VUT FSI.

PLUHAŘ, J. - PUŠKÁR, A. - MACEK, K. 1987. Physical Metallurgy and Material Limit States. $1^{\text {st }}$ ed. Praha : SNTL, 420 pp.

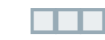

